\title{
As cartas de Tell El-Amarna e o contexto egípcio nos reinados de Amenhotep III e Amenhotep IV (Akenaton)
}

\author{
José Ademar Kaefer*
}

\section{Resumo}

A descoberta das cartas de Tell El-Amarna foi um dos maiores achados do século XIX a respeito da história do mundo antigo. Elas revelaram para o mundo moderno o nível e a forma das transações políticas e econômicas existentes entre o Egito e os reinos do Antigo Oriente Próximo no final do segundo milênio a.C. Um total de 382 correspondências encontradas num único sítio arqueológico surpreenderam ao testemunhar a intensa atividade literária e a sofisticada rede de relações diplomáticas que então já existiam. Desvelar o contexto histórico do Egito correspondente aos reinados de Amenhotep III e Amenhotep IV (Akenaton), que produziu essas cartas, é o objetivo deste artigo. Isso permitirá uma melhor compreensão do conteúdo das cartas de El-Amarna, bem como, da realidade sociopolítica e econômica de Canaã, região que pouco tempo depois será palco da formação do então povo de Israel.

Palavras-chave: Egito. Amenhotep III. Amenhotep IV (Akenaton). Tell El-Amarna. Canaã.

\section{The Tell El-Amarna letters and the Egyptian context in the Amenhotep III and Amenhotep IV (Akhenaten) Reigns}

\begin{abstract}
The discovery of Tell El-Amarna letters was one of the greatest discoveries of the nineteenth century on the history of the ancient world. They revealed to the modern world the level and form of political and economic transactions between Egypt and the kingdoms of the ancient Near East at the end of the second millennium BC. 382 correspondences found in a single archaeological site surprised when they showed the intense literary activity and the sophisticated network of diplomatic relations that then existed. Unveil the Egyptian historical context corresponding to the reigns of Ame-
\end{abstract}

* Doutor em Ciências da Religião e professor do Programa de Pós-Graduação em Ciências da Religião da Universidade Metodista de São Paulo. E-mail: jademarkaefer@yahoo.com 
nhotep III and Amenhotep IV (Akhenaten), who produced these letters, is the aim of the present article. This will make possible a better understanding of the content of the El-Amarna letters, as well, as of the socio-political and economic reality of Canaan, the region whom will be the scene of the formation of Israel people.

Key-words: Egypt. Amenhotep III. Amenhotep IV (Akhenaten). Tell El-Amarna. Canaan.

\section{Las cartas de Tell El-Amarna y el contexto egipcio en los reinados de Amenhotep III y Amenhotep IV (Akenatón)}

\section{Resumen}

El descubrimiento de las cartas de Tell El-amarna fue uno de los mayores hallazgos del siglo XIX sobre la historia del mundo antiguo. Ellas revelaron al mundo moderno el nivel y la forma de las transacciones políticas y económicas existentes entre Egipto y los reinos del Antiguo Oriente Próximo en el final del segundo milenio a.C. 382 correspondencias encontradas en un único sitio arqueológico sorprendieron al testimoniar la intensa actividad literaria y la sofisticada red de relaciones diplomáticas que entonces ya existían. Desvelar el contexto histórico de Egipto correspondiente a los reinados de Amenhotep III y Amenhotep IV (Akenaton), que produjo estas cartas, es el objetivo de este artículo. Esto tornará posible una mejor comprensión del contenido de las cartas de El-amarna, así como de la realidad socio, político y económica de Canaán, región que poco tiempo después será el escenario de la formación del entonces pueblo de Israel. Palabras clave: Egipto. Amenhotep III. Amenhotep IV (Akenatón). Tell El-Amarna. Canaán.

\section{Introdução}

Quando encontradas no século XIX e início do século XX da nossa era, as cartas de Tell El-Amarna surpreenderam o mundo ao revelar a existência de uma sofisticada rede de relações diplomáticas entre os grandes e pequenos reinos do Oriente Próximo e o Egito do século XIV a.C., desconhecidas até então. Essas relações não se davam somente entre o Egito e os reinos vassalos e ou os grandes centros de poder amigos, mas também entre os próprios poderes locais, que também já dominavam a escrita. De forma que, as cartas de El-Amarna se tornaram uma importantíssima fonte para o estudo da cultura, não só do Egito e dos grandes reinos da Mesopotâmia, como a Babilônia, Assíria e Damasco, mas também da Anatólia, Mitani, Hati, Arzawa etc. do período do Bronze Tardio. E, evidentemente, dos pequenos reinos vassalos de Canaã, mais próximos geograficamente do Egito e de maior interesse do presente estudo. Assim, todo material de Amarna representa ser uma chave para a compreensão da ponte entre as culturas do Egito e do Oriente Próximo, que influenciaram direta ou indiretamente a cultura pré-bíblica, onde mais tarde surgiria o povo do então Israel (MYNAROVÁ, 2015b, p. 412). 
Contudo, na América Latina e Caribe, em particular no Brasil, o campo da Bíblia ainda carece de um estudo das cartas de El-Amarna. Em geral, costuma-se fazer referências a elas em livros e artigos bíblicos, mas raros são os estudos que tratam especificamente do tema. A meta deste artigo e de outros que virão ${ }^{1}$ é ajudar a diminuir essa conjuntura deficitária. A primeira parte se ocupará basicamente do período que corresponde ao reinado de Amenhotep III. Em seguida, se tratará da construção e queda de Aketaton, ou Tell-el Amarna, tendo como foco de análise a política de Amenhotep IV, também conhecido como Akenaton. E, por fim, se abordará a história da escavação de Tell El-Amarna e a descoberta das cartas, apoiado principalmente nos estudos recentemente publicados de Anson Rainey e de Jana Minarová.

\section{A estabilidade política e econômica da XVIII Dinastia}

Antes de começar a tratar das cartas de El-Amarna propriamente dito, é importante ter em mente, ainda que muito sucintamente, o que representava o império egípcio para os povos vizinhos durante o século XIV a.C. Quando se visita as escavações dos sítios arqueológico em Israel e Palestina do tempo que corresponde às cartas de El-Amarna e depois se dirige ao Egito e se vê as escavações ali não tem como não ficar assombrado com a enorme disparidade. É praticamente impossível estabelecer uma comparação entre os monumentos cananeus e os egípcios.

A riqueza do Egito suplantou todos os impérios. Não existiu um império igual ao egípcio, nem antes nem depois dele, com tanto poderio econômico e um domínio tão longo. As magníficas obras, fruto em grande parte da exploração de mão de obra escrava e de tributos oriundos das mais remotas regiões, durante três milênios, impressionam o mundo ainda hoje e continuam sendo a maior fonte de renda do Egito atual. ${ }^{2}$ Não somente as pirâmides, construídas em sua maior parte durante o Antigo Império (3200-2100), ${ }^{3}$ mas

1 Este artigo tem como objetivo central a apresentação do contexto egípcio durante o período em que as cartas de Tell el-Amarna foram escritas. Dessa forma, se terá uma base sólida para outros artigos que se seguirão e que tratarão especificamente do conteúdo das cartas de Amarna e do contexto de Canaã.

2 O que os faraós, melhor seria dizer escravos, construíram quatro e cinco mil anos atrás ajuda, ainda hoje, a manter o Egito.

3 Inicialmente, as pirâmides eram apenas tumbas, que, ao serem construídas umas sobre as outras, foram tomando a forma piramidal. Depois foram perdendo a função de tumba para se tornarem monumentos de ostento de riqueza e poder. Com a terça parte superior das pirâmides pintada a ouro e com o sol refletindo nelas, a vista a quilômetros de distância causava uma impressão de poder única no mundo. 
também outras obras, como estátuas gigantescas esculpidas em montanhas, ${ }^{4}$ como as de Ramsés II e sua mulher e filho em Abu Simbel, ${ }^{5}$ a esfinge de Gizé, ${ }^{6}$ centenas de impressionantes obeliscos talhados em peça única, ${ }^{7}$ magníficos templos e palácios (CHALABY, 2001), ${ }^{8}$ são exemplos da imponência do que foi esse império milenar. ${ }^{9}$

Comparada à longa história do Egito, as cartas de Amarna compreendem um período bastante curto. Resumem-se basicamente ao contexto do reinado de dois reis ou faraós: Amenhotep III (Amon está satisfeito) ${ }^{10}$ e Amenhotep IV, também conhecido como Akenaton. As datas que tratam do período do reinado dos reis egípcios não são muito exatas, variam conforme alguns documentos. ${ }^{11}$ Em geral, prevalecem as datas de 1390-1352 para Amenhotep III e 1352-1336 para Amenhotep IV (MORAN,1992, p. 39).

4 Um intento de réplica das imagens dos presidentes dos EUA no Monte Rushmore.

5 Nome do menino que teria encontrado o templo, que mais tarde foi transferido de lugar por causa da barragem que inundou as margens do rio Nilo.

6 Cuja face parece ter sido desfigurada pelos cristãos na conquista napoleônica.

7 O maior deles (cerca de 42 metros), conhecido como o "obelisco de Aswan", não foi terminado porque sofreu uma rachadura, mas, que está à vista do público. A partir do Egito, os obeliscos se tornaram símbolo de monumentos comemorativos no mundo e são encontrados hoje nas principais praças das grandes cidades, por exemplo, o obelisco de Washington. Muitos obeliscos foram transportados do Egito pelos conquistadores europeus, como o que se encontra no centro da Praça de São Pedro, e acima do qual foi colocada uma cruz. O curioso é que os obeliscos egípcios eram um símbolo do culto ao Deus Sol, Amon Rá.

8 Mesmo durante o primeiro milênio a.C., quando vai perdendo espaço para os novos impérios da Assíria, Babilônia, Persa, Grécia e finalmente Roma, o Egito continua sendo um centro de poder e riqueza. Basta mencionar, por exemplo, o Faro, que com os seus 137 metros de altura é o maior farol já construído. Ou a célebre biblioteca de Alexandria, maior centro do saber do mundo antigo.

9 O destino da riqueza dos reis é cercado de mistério. É fato que muitas tumbas foram saqueadas antes de serem encontradas pelos arqueólogos. Contudo, mesmo as que não foram, o paradeiro do tesouro que costumava ser guardado dentro delas é desconhecido. Uma das poucas exceções é a tumba de Tutancâmon (13361327), encontrada em 1992 no Vale dos Reis. Ali foram achados, entre outros objetos valiosos, dois tronos de ouro, bigas de ouro, o sarcófago com o interior todo de ouro, uma máscara mortuária etc. Se esse rei, que ao que se sabe morreu assassinado ainda adolescente, possuía tanto ouro, imagine-se a riqueza de um faraó poderoso como Ramsés II, que reinou quase setenta anos.

10 Ou do grego Amenófis.

11 Veja amplo panorama da cronologia egípcia em: Daphna Ben-Tor (Org.) "Pharaoh in Canaan - The Untold Story", p. 15-17. Também em: http://antigoegito.org/cronologiadinastias/ (acessado em 24/06/2017). 
Portanto, um período em torno de 50 anos. Ambos os reis pertenciam à XVIII dinastia, que foi o responsável pela expulsão definitiva dos hicsos do Egito. ${ }^{12}$ Com essa dinastia se instaura o Novo Império, quando o Egito volta a se expandir, principalmente em direção ao norte, até as fronteiras da Anatólia, e ao leste, até as fronteiras do Eufrates. Mas também para o sul, Sudão, e para o noroeste, em direção à Ásia Menor, na região do Mediterrâneo, anexando reinos menores como Núbia, Alishia, Creta e os reinos egeus (MURNANE, 1995, p. 2-4). O Egito alcança construir relações de paz relativamente estáveis com as grandes forças da época, Babilônia, Assíria, Damasco, Mitani e o seu arqui-inimigo, o império hitita. As cartas de Amarna retratam em geral boas relações diplomáticas com todos esses reinos.

Com o seu centro administrativo na capital Tebas, ${ }^{13}$ a $312 \mathrm{~km}$ ao sul da cidade do Cairo, a XVIII dinastia conseguiu unificar novamente o Alto e o Baixo Egito, sob uma mesma monarquia. ${ }^{14}$ Pelas construções e a expansão comercial, retratada nas cartas, o Novo Império, particularmente os anos que vão de 1580 até o final do segundo milênio a.C., foi provavelmente o tempo de maior estabilidade política e econômica na longa história do império egípcio.

\section{Amenhotep III e o poder dos sacerdotes}

A estabilidade política e econômica conquistada pela XVIII dinastia, principalmente durante o reinado de Tutmosis IV (1400-1390), permitiu a Amenhotep III um reinado relativamente tranquilo, pelo menos externamente, sem necessidade de muito investimento em guerras (RAINEY, 2015, p. 14-15). As cartas de El-Amarna identificadas como sendo de Amenhotep III mostram uma habilidade bastante desenvolvida no uso da diplomacia para solucionar conflitos. Isso permitiu que esse rei pudesse se ocupar com grandes construções que guardariam sua memória. A tal ponto que Amenhotep III seja considerado hoje o maior construtor na história do Egito. Um exemplo é o seu templo-mortuário construído em Tebas, com as gigantescas estátuas, dele e de sua mulher, na entrada do templo, cujas paredes medem 750 metros de comprimento. Ou seja, a riqueza e a estabilidade política permitiram que

12 A invasão dos hicsos, por volta de 1750, durou cerca de 170 anos. Sua expulsão, entre os anos 1580-1525, serve como marco do fim do Médio Império e início do Novo Império, com a XVIII dinastia.

13 Onde se encontra o famoso templo de Karnak, cuja estrutura, com suas imponentes colunas, está bem preservada até hoje.

14 Os reis que dominaram sobre o Alto e Baixo Egito são identificados pelo uso da dupla coroa. A branca representava o Alto Egito e a vermelha o Baixo Egito, também conhecido por Ta-Mehu, que significa "terra do papiro". 
Amenhotep III pudesse se ocupar com a arte e com questões da política interna do país, principalmente as relacionadas à religião. Amenhotep III habilmente unifica o culto ao Deus $\mathrm{Ra}^{15}$ de Heliópolis, do Baixo Egito, com Amon, o Deus de Tebas, ${ }^{16}$ do Alto Egito. Dessa fusão, resultou Amon-Ra, o deus supremo do panteão egípcio (RAINEY, 2015, p. 17).

O Egito, apesar de ser uma monarquia, pois no topo do poder estava o monarca, seu governo funcionava bem mais como uma teocracia. O rei ou faraó era considerado um deus, ou o representante dele, e governava como um deus ou em nome dele. Os sacerdotes tinham um poder enorme na sociedade egípcia. Pode se dizer que em última instância a religião era a responsável pelo equilíbrio social do país. Tal estabilidade era atribuída à Maat, uma deusa com asas de plumas, que representava a justiça, similar ao o que o povo de Israel denominava de $s^{e} d a q a h$. Aqui como lá, a justiça é feminina. Os rituais de oferenda à Maat tinham essa função, a de manter o equilíbrio, para que na ausência do sol, a escuridão da noite não triunfasse (TRIGGER; KEMP; O'CONNOR; LLOYD, 1999, p. 188-191). As abundantes ofertas não vinham só do Egito, mas de todo o império e eram controladas pelos sacerdotes (MURNANE, 1995, p. 162-163). A estrutura do templo tinha a finalidade de contribuir nessa sensação de poder e equilíbrio. Rodeado por uma enorme muralha, o interior era dividido por três grandes portões, em grego chamados de "pilonos". ${ }^{17}$ Depois do primeiro portão encontrava-se um grande pátio, com um grande altar no centro, e mesas menores para as ofertas. Uma rampa dava acesso ao altar. Depois do segundo portão havia outro pátio, onde se encontrava a casa do sumo sacerdote. E, por fim, um terceiro portão, que dava acesso ao santo dos santos, onde só o sacerdote e o faraó podiam entrar, pois era a morada do Deus Amon-Ra (TRIGGER; KEMP; O'CONNOR; LLOYD, 1999, p. 198). Acredita-se que em Karnak trabalhassem cerca de setenta a oitenta mil funcionários, com mais de mil sacerdotes. De maneira que, mais do que um templo, Karnak era um complexo de vários templos, com armazéns para estocar tributos, padarias, tecelarias, escolas etc.

A escrita hieroglífica, em boa parte, era dominada somente pelos sacerdotes. Era outra forma de poder. Considerada sagrada, era o meio por excelência para se comunicar com os deuses. Os templos, tumbas, palácios e monumentos eram repletos de hieróglifos. Seus tons coloridos embelezavam e faziam o Egito parecer uma nação sagrada.

\footnotetext{
15 Ou Re.

16 Atual Luxor.

$17 \pi u \lambda \dot{\omega} v$ : porta grande.
} 


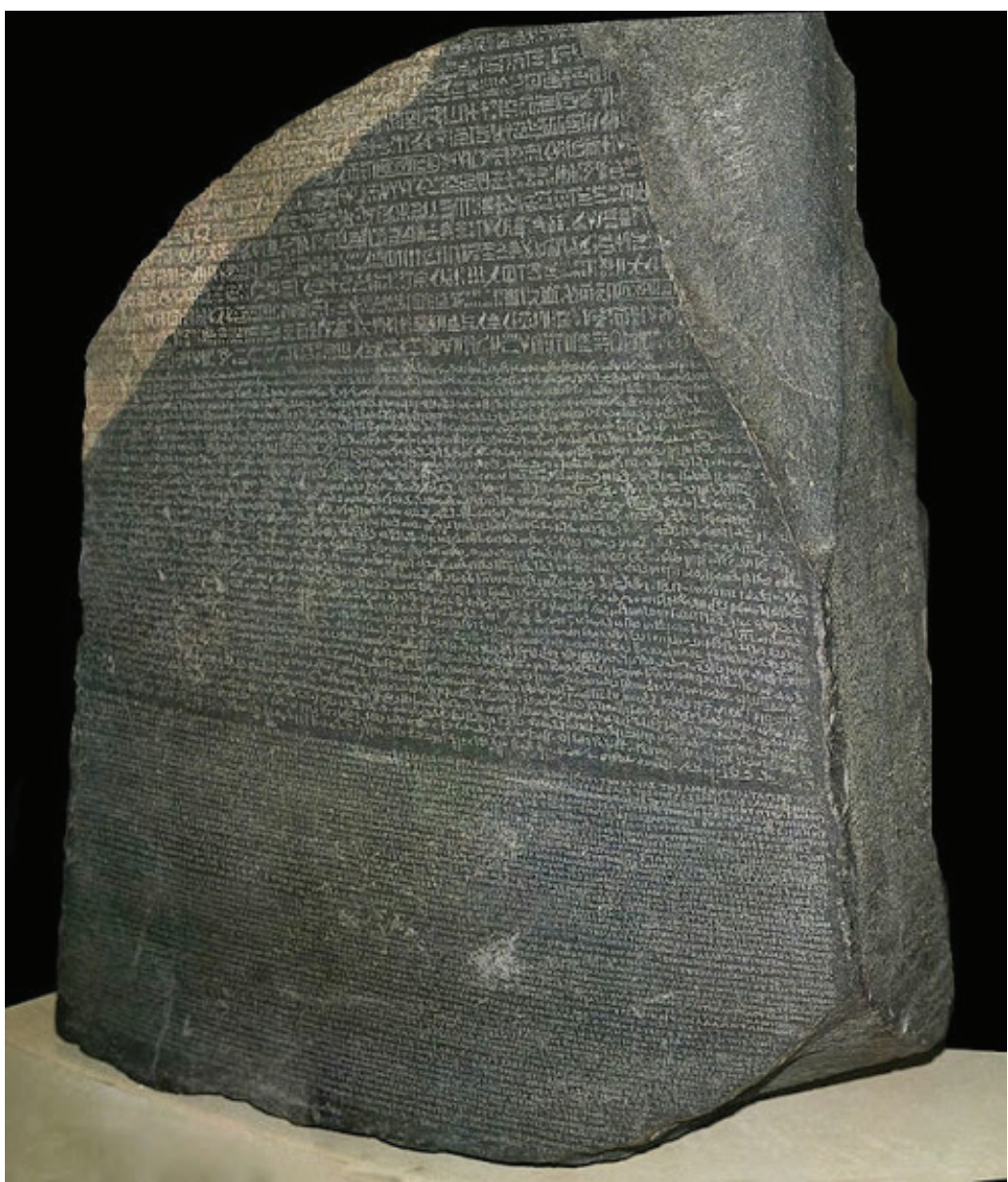

A Pedra de Roseta, um decreto de 196 a.C. feito por Ptolomeu V. Nele o rei faz concessões tributárias escritas em três línguas: a parte superior em hieróglifo, a do meio em egípcio antigo e a inferior em grego clássico. Graças a ela foi possível ao mundo moderno decifrar os hieróglifos, desconhecidos até o princípio do século XIX (http://www.museudeimagens.com.br/pedra-de-roseta). ${ }^{18}$

18 Mesmo vivendo em Alexandria, os gregos não aprendiam a língua egípcia, por isso os funcionários egípcios eram obrigados a aprender o grego. O povo, porém, tinha muita dificuldade, razão pela qual os decretos tinham que ser escritos em três línguas ou mais. A Pedra foi encontrada em 1798, em El-Rashid, Egito, por Napoleão e sua comitiva, seguida por uma longa disputa entre franceses e ingleses pela sua posse. Em 1822, o francês Jean-François Champollion decifrou os hieróglifos. O mundo pôde, então, entender o significado desses sinais milenares nos monumentos egípcios. Tudo isso fez da Pedra de Roseta o objeto mais popular do museu britânico (MacGREGOR, 2013, p. 245-251). 
Além disso, os sacerdotes administravam uma enorme quantidade de terras, tinham bens, escravos, animais etc. A mumificação era outra grande fonte de renda do país administradas pelos sacerdotes. A mumificação era uma atividade intensa e permanente no Egito. O número de pessoas mumificadas na história do Egito é incontável. Enfim, acredita-se que os sacerdotes controlavam em torno de um terço da riqueza do país. Era um Estado dentro do Estado. Essa estrutura ideológica parece que não era muito contestada pela população egípcia, que via na ação dos sacerdotes a razão da proteção do Egito. Com as permanentes bênçãos das águas do Nilo, o Egito era uma nação protegida pelos deuses. Graças à boa conduta dos sacerdotes, o povo egípcio, comparado às nações vizinhas, vivia em grande abundância.

Contudo, ao que parece, Amenhotep III, com seu exército, não partilhava dessa opinião. Para ele, o poder dos sacerdotes era demasiado grande, a ponto de chegar a fazer sombra ao seu próprio poder. Parece que os sacerdotes tinham mais influência e controle sobre o povo do que o próprio faraó. É provável que essa tensão entre os dois poderes já viesse do tempo de Tutmosis IV, pai de Amenhotep III. Ou seja, a riqueza e a paz construídas pelos reis da XVIII dinastia, que antecederam Amenhotep III, e que agora estavam sendo usufruídas, conduziram a um conflito interno que ameaça levar o Egito à deriva. Ainda que a revolução vá eclodir somente com Amenhotep IV, já com Amenhotep III percebe-se uma mudança na arte e na teologia. Há maior ênfase na pessoa do rei, como se pode ver nas enormes estátuas do templo de Tebas, que expressam grande superioridade e segurança. Ali, Amenhotep III, com sua mulher, se parece mais como deus do que como rei. O rei-deus vai se transformando no deus-rei. Contudo, Amenhotep III habilmente ainda consegue manter o equilíbrio social, sem levar essa ideologia do deus-rei ao extremo, mas não assim seu filho e sucessor.

\section{Do esplendor à crise: Aketaton e o culto a ATON, o disco solar}

Com a subida ao poder de Amenhotep IV (1352-1336), o conflito entre a família real e a classe sacerdotal se acirra. O exército está do lado do rei. Todos os ministros do futuro governo serão militares (RAINEY, 2015, p. 15). Mas, o poder dos sacerdotes era muito grande. A forma de anular esse poder seria destituir Amon-Ra e elevar a Aton, o deus sol, representado pelo disco solar e seus raios, como único deus. Assim sendo, Amenhotep IV começa uma forte perseguição ao culto de Amon-Ra. Manda fechar o templo em 
No-Amon, quebrar as imagens e arrancar o nome de Amon-Ra das paredes dos templos pelo Egito afora. Em contrapartida, constrói um templo novo a Aton, justamente ao lado do templo de Amon-Rá em Karnak. Esse novo templo foi construído muito rapidamente, utilizando uma nova engenharia. Em vez dos grandes e pesados blocos de pedra, difíceis de transportar, o que delongava a conclusão da obra, os engenheiros de Amenhotep IV fabricam pequenos blocos de cal, chamados talatat,$^{19}$ que facilitava o transporte e agilizava a construção. Essa mesma engenharia será utilizada nas futuras construções da nova capital em Aketaton. O novo templo também apresenta uma forma inusitada, que igualmente se verá nos templos de Aketaton, não tinham teto. Os templos de Aton são todos descobertos a fim de que os raios do disco solar possam brilhar em seu interior.

Ao promover Aton como único deus, Amenhotep IV busca promover a si mesmo e destronar o poder dos sacerdotes, cuja mediação já não é mais necessária. Agora, Aton está na terra, na pessoa do próprio rei e da família real. Essa mudança estremeceu toda a estrutura ideológica do Egito e teve um impacto enorme na economia e política do país.

\subsection{Aketaton: a Tell El-Amarna}

Introduzir uma nova teologia, com um único deus, mudando assim uma visão de mundo que perdurara milênios, era uma empreitada complexa e nada fácil. Amenhotep IV chega à conclusão de que é necessária uma mudança radical. Tebas estava demasiadamente contaminada pela velha teologia, que impedia o brilho do novo deus e do novo faraó. Amenhotep IV, agora autodenominado Akenaton, ${ }^{20}$ teria tido um sonho, que Aton lhe revelara uma missão: construir uma nova capital num lugar totalmente virgem e isolado. $\mathrm{O}$ lugar escolhido ficava no meio do deserto, numa planície na margem oriental do rio Nilo, a 290 quilômetros ao norte de Tebas. ${ }^{21}$ E chamaria Aketaton. ${ }^{22} \mathrm{~A}$ vista faz jus ao nome. Aketaton fica de frente a duas montanhas, entre as quais surge o sol da manhã com seus raios inundando a cidade (KEMP, 2012, 36-39).

Usando a nova engenharia dos talatat, a construção da nova capital se deu de maneira bastante rápida, sendo inaugurada no quinto ano do reinado

\footnotetext{
19 Significado incerto. Talvez, derivado do arábico, signifique "largura de três mãos", em referência à sua dimensão (SHAW; NICHOLSON, 2002, p. 281-282).

20 "Benéfico a Aton."

21 A meio caminho entre Menfis e No-Amon.

22 "Horizonte de Aton."
} 
de Akenaton. Acredita-se que com dois anos de fundação, a cidade já contava com 20 mil habitantes. O arquétipo da cidade também era inovador. Fora planejado matematicamente a partir do ponto onde seria construída a tumba de Akenaton e por onde o sol nascente projetava seus raios sobre toda a cidade. O comprimento da cidade ao longo da margem do rio Nilo era de $12 \mathrm{~km}$, por $5 \mathrm{~km}$ de largura. Ao todo, a cidade cobria 60 mil quilômetros quadrados. Paralelo ao rio, uma via principal seguia todo o comprimento da cidade, e era conhecido como o caminho real. Grandes monumentos com cores vivas, palácios e templos acompanhavam o percurso da via real. Dez estelas talhadas em rochas demarcavam os limites da cidade (MYNAROVÁ, 2015, p. 410). A mais famosa é a estela denominada letra $\mathrm{U}$, que mede em torno de 7,5 metros de altura e delimitava a parte nordeste da cidade, perto da tumba real. $\mathrm{Na}$ parte superior da estela, encontra-se a família real sendo banhada pelos raios de luz do disco solar. $\mathrm{Na}$ parte inferior, um longo texto em hieróglifos, no qual se narra, entre outros, a missão que Akenaton teria recebido do Deus Aton, de construir ali a cidade (KEMP, 2012, p. 33).

Nos anos que se seguiram, Akenaton coloca em prática a nova teologia monoteísta. As figuras nos templos e palácios retratam uma atenção centrada na família real. ${ }^{23}$ Muitos desenhos representando o casal, Akenaton e Nefertiti, em adoração ao disco solar, Aton. ${ }^{24}$ A situação social do povo e o contexto político do império são secundários para Akenaton e a família real. As cartas de El-Amarna, que podem ser atribuídas a Akenaton, mostram um forte declínio do controle político e militar dos territórios conquistados pelos seus antecessores.

23. Essa ênfase do Deus na terra e na pessoa e família de Akenaton traz também outra visão de mundo, não para fora, mas para dentro, para este mundo. De modo diferente de outros períodos da história do Egito, no de Amarna as pinturas dão maior realce ao indivíduo e ao cotidiano da vida, de um Deus presente na história.

24 Os diferentes estilos da arte também expressam a nova teologia, bastante distinta da dos antecessores de Akenaton. Enquanto os reis anteriores eram retratados em pé e em movimento, com ombros largos, rosto quadrado, musculosos e semblante guerreiro, Akenaton aparece sentado, com a esposa e filhos, carinhoso, braços, mãos e dedos finos e compridos, sem musculatura, estatura delgada e alta, cabeça, pescoço e rosto alongados, com expressão suave, coxas e quadris avantajados. Também as mulheres aparentam ter mais participação nas decisões durante o governo de Akenaton. Um exemplo é sua mulher, Nefertiti (KEMP, 2012, 31). Veja a comparação dos estilos em: http://www.nationalgeographic. $\mathrm{com} / \mathrm{magazine} / 2017 / 05 /$ akhenaten-revolutionary-egypt-king-art-architecture/ (acessado em 26/06/2017). 


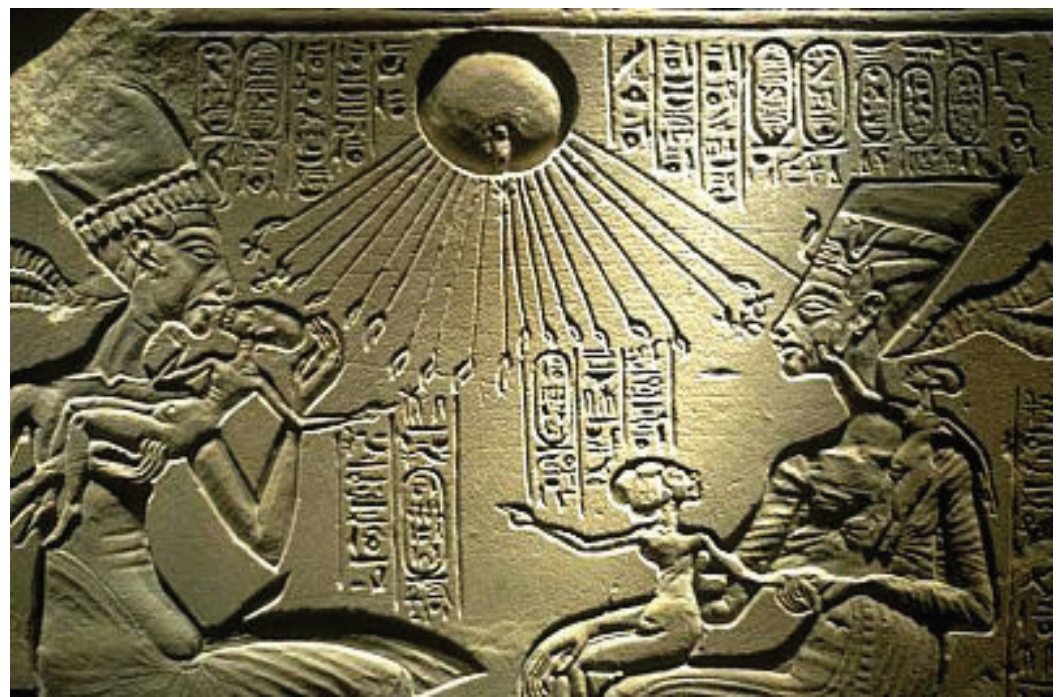

Akenaton com a familia real e o disco solar (http://www.auladearte.com.br/historia_da_arte/ egito.htm\#axzz4pMCJzJKj)

\subsection{O fim de Aketaton e da revolução de Akenaton}

Akenaton morre em 336 a.C., após dezessete anos de reinado. Um tempo extremamente curto para mudar uma religião milenar. Apesar da repressão, o culto às divindades dos antepassados continuava às ocultas no meio popular (MURNANE, 1995, p. 6). Akenaton havia destituído o panteão egípcio, mas ele continuava bem vivo no imaginário da população. Impossível mudar a mitologia de um povo em uma ou duas décadas. O politeísmo era uma questão de identidade cultural do povo egípcio. Ademais, não bastava dizer que Aton criara o mundo, sem que existissem mitos que explicassem como.

Enfim, a tentativa de introduzir o monoteísmo levou o Egito ao caos. Não só internamente, mas também em todo o Levante, onde se encontravam os territórios anexados. As cartas de El-Amarna, que podem ser atribuídas ao governo de Akenaton, mostram um império em crise. As cidades-Estado não se cansam de pedir ao faraó o envio de tropas regulares para proteger suas cidades de ataques inimigos. Em Canaã, as principais cidades-Estado, como Siquém, Gezer, Gat e Jerusalém, começam a disputar entre si o controle dos territórios. A falta da presença de forças do exército egípcio na região também faz crescer os movimentos rebeldes, como o dos hapirus, cujas ações são uma constante nas cartas de El-Amarna. Ou seja, o que foi ruim para o Egito 
foi bom para os reinos vassalos que, por primeira vez, depois de séculos de domínio quase ininterrupto, respiram ares de liberdade. ${ }^{25}$

Não se sabe ao certo quem foi o sucessor imediato de Akenaton. Há indícios de que tenha sido seu filho Semencaré (1336-1334), ou talvez a própria Nefertiti, mulher de Akenaton (MURNANE, 1995, p. 10-11). Semencaré desaparece misteriosamente e quem assume o poder em seu lugar é Tutankaton (1334-1321). É possível que por detrás do sumiço de um rei e da entronização de outro estivesse um amplo movimento sacerdotal para restabelecer a antiga religião. E assim parece ter sido, pois uma das primeiras ações de Tutankaton é a mudança do seu próprio nome para Tutankamon, ${ }^{26}$ o que por si sugere a restituição de Amon como o deus supremo da religião oficial egípcia.

$O$ agora Tutankamon coloca um fim radical na revolução de seu pai, abandona a cidade de Aketaton, restabelece a capital em Tebas e autoriza a volta do culto ao deus supremo Amon-Ra. Não satisfeito, e para justificar a nova política, maldiz o legado de seu pai e proclama em estelas a corrupção dos juízes e militares e o caos em que o país estava imerso (RAINEY, 2015, p. 15). A destruição que aconteceu com os templos de Amon-Rá acontece agora com os templos de Aton. Após a destruição dos templos, os pequenos blocos de baixo relevo da engenharia de Akenaton, conhecidos como talatat, muitos deles contendo hieróglifos, são reutilizados em outras construções novas, prédios públicos, pisos, muros etc., em diferentes cidades. O fator positivo dessa ação é que com isso os talatat foram preservados. Reagrupá-los novamente se consiste num verdadeiro quebra-cabeça.

Enfim, com a morte de Akenaton, morre sua revolução. A cidade de Aketaton é abandonada e esquecida, e só irá ressurgir mais de três milênios depois, como El-Amarna. E ficará famosa pelas centenas de correspondências ali encontradas.

\section{As escavações em Tell El-Amarna (AKETATON)}

Depois de ser abandonada, Aketaton foi lentamente sendo apagada da memória do povo egípcio, apesar do local, com suas construções depredadas, continuar à vista de quem por ali navegasse pelo rio Nilo. ${ }^{27} \mathrm{O}$ espectro da outrora fabulosa cidade de Akenaton sobrevivia ao tempo e, mesmo que rara-

\footnotetext{
Esse será o tema central do nosso artigo seguinte.

26 De quem, como já mostrado, foi encontrada a tumba com grande quantidade de riquezas.

27 A sua preservação permite que ainda hoje a cidade seja uma referência para o estudo da vida urbana do Egito antigo.
} 
mente, continuava a ser visitada por viajantes curiosos. Até que no início do século XIX, da nossa era, começou a despertar o interesse de arqueólogos por suas inscrições desconhecidas e por suas tumbas depredadas. A desconhecida cidade passou, então, a ser chamada de Tell El-Amarna. Conforme, Rainey (2015, p. 1), por um mal-entendido dos nomes da vila et-Til e da tribo banu Amram, que vivia nos arredores.

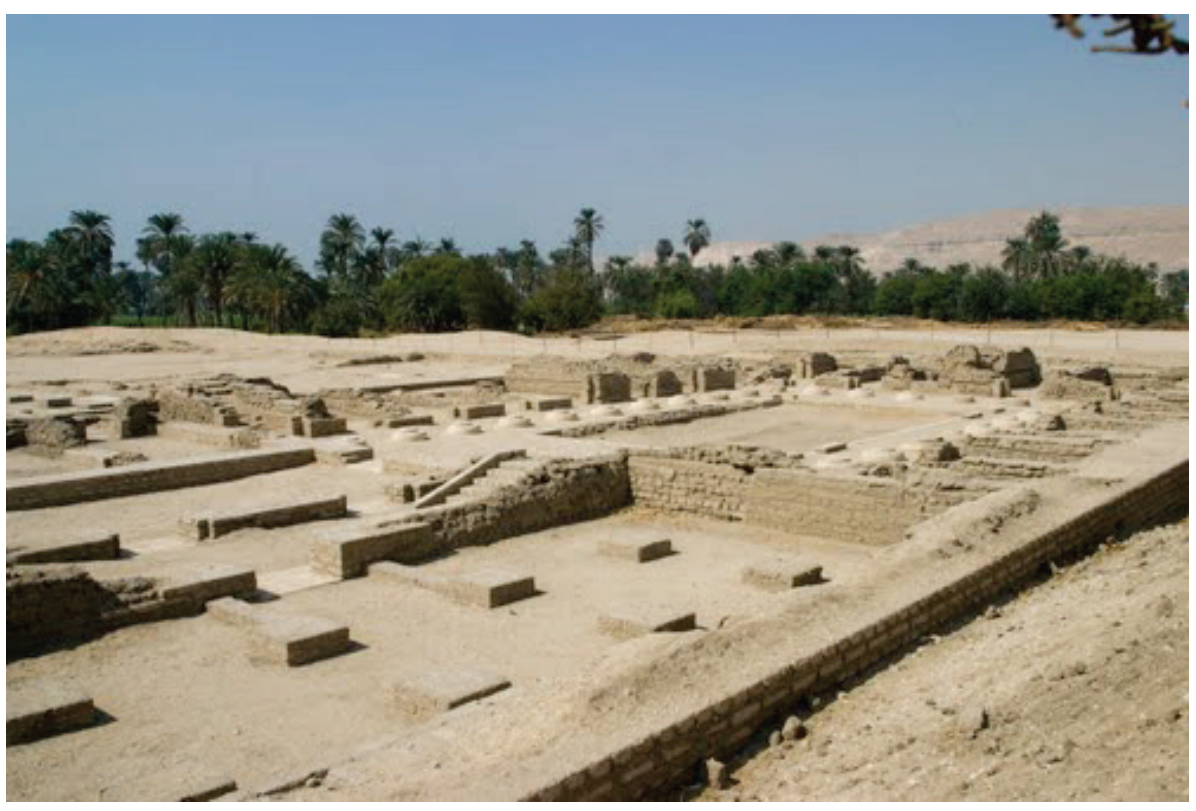

Parte do grande templo de Akenaton em El-Amarna (foto: google earth)

Apesar de ter havido várias escavações anteriores, prioritariamente à procura de tesouros, a primeira moderna escavação foi a que o britânico William Matthew Flinders Petrie conduziu entre 1889 e 1892. Flinders inaugurou uma nova técnica de fazer arqueologia, principalmente no que se refere ao estudo e classificação dos estratos arqueológicos. Foi ele quem descobriu a importância da cerâmica para classificar a sequência cronológica dos estratos (DAVIS, 2004, p. 28). ${ }^{28}$ As primeiras cartas, que deram início à corrida à Tell

28 Ao escavar um cemitério pré-histórico, Petrie percebeu as grandes diferenças nos potes de cerâmica junto aos restos mortais nas tumbas. Analisando a cerâmica, Petrie conseguiu datar a sequência cronológica dos diferentes tipos e estilos, seu surgimento e declínio, que ele correlacionou com os diferentes grupos étnicos. A análise tipológica de Petrie fixou-se prioritariamente no estilo da asa dos potes. Petrie iniciou também uma nova consciência arqueológica ao denunciar o estrago que a arqueologia fazia para a história e para o futuro, 
el-Amarna, contudo, foram encontradas já em 1887. Conforme a conhecida versão, elas teriam sido achadas de forma acidental por uma mulher que estava à procura de adubo orgânico para a sua horta. Essa versão foi contestada por Jana Mynarová ${ }^{29}$ e teria sido inventada para ocultar o verdadeiro processo do achado (2015, p. 37-46). Segundo uma pesquisa feita nos registros do museu do Cairo, Minarová descobriu que ali consta a aquisição de objetos vindos de El-Amarna já em maio de 1887. Encontra-se registrado, inclusive, o nome do vendedor, Farag Ismain. Ao contrário, portanto, como conhecido oficialmente de que os tabletes teriam sido descobertos no final de 1887 , já se sabia de sua existência na primavera ou até no verão desse ano.

Mynarová lamenta a pouca ou quase nenhuma informação a respeito do processo das escavações dos tabletes registrado nos arquivos da Sociedade de Exploração Egípcia. Eles indicam somente a data da descoberta, que agora é contestada. Da mesma forma, também William Petrie não especifica em suas publicações onde exatamente os tabletes foram encontrados. ${ }^{30}$ De maneira que, segundo Mynarová, sobre o local exato dos achados, temos informações seguras somente de cerca de $10 \%$ dos tabletes. Nesse sentido, a versão de Petrie, de que as cartas foram encontradas num lixão, onde teriam sido jogadas quando a cidade foi abandonada e posteriormente seladas embaixo de construções, também se encontra sob grande suspeita (RAINEY, 2015, p. 3).

Com a descoberta das primeiras cartas, cuja forma e local exato talvez jamais se saiba, seguiram-se sucessivas expedições que perduraram até os anos de 1980. Portanto, um século de escavações. Ainda que o grosso do montante tenha sido achado no início por William Petrie, as expedições seguintes também encontraram algumas cartas. Mas, os achados não se resumem às cartas, também foram encontrados vários artefatos valiosos, como o belo busto da rainha Nefertiti, mulher de Akenaton, encontrado pela expedição de 19111914, coordenada por Ludwig Borchardt.

principalmente quando um objeto é retirado do seu meio sem uma detalhada descrição. Insistia na necessidade de se proteger o sítio para que no futuro outros, com técnicas inovadoras, pudessem continuar a escavação. Foi ele quem introduziu os planos topográficos, o corte em valas e outras técnicas com o objetivo de preservar o Tel (DAVIS, 2004, p. 28-29).

29 Jana Mynarová, egiptóloga da universidade de Praga, especialista em textos acádicos e línguas semitas, trabalhou com Anson F. Rainey. Veja sua vasta publicação acerca do tema em: https://cuni.academia.edu/JanaMynarová.

30 É bem verdade que as demolições feitas pelos trabalhadores da XIX dinastia egípcia e, principalmente, de escavadores clandestinos à procura de antiguidades deve ter removido a terra de tal forma, que prejudicou para sempre a classificação precisa da estratigrafia. 
Enfim, até os dias atuais foram encontradas 382 cartas. Apesar de muitas em estado fragmentado, a maioria se acha bem preservada. ${ }^{31} \mathrm{~A}$ conclusão unânime é de que elas correspondem ao período do reinado de dois reis: Amenhotep III e Amenhotep IV, também conhecido como Akenaton. Quando o último abandonou Tebas e se mudou para a sua cidade, Akentaton, hoje El-Amarna, seus ministros das relações exteriores levaram consigo boa parte das correspondências que Amenhotep III enviara e recebera de seus correspondentes internacionais. Quando a cidade de Aketaton (El-Amarna) foi abandonada, após a morte de seu fundador, também as cartas foram deixadas, tanto as de Amenhotep III quanto às escritas por Akenaton. O real motivo é desconhecido, mas uma possível razão talvez seja porque as cartas estavam obsoletas ou porque a nova realeza queria começar uma nova era e para isso era necessário cortar todos os laços com o passado recente. O fator positivo é que com isso elas foram preservadas e, quando encontradas, tornaram-se o maior achado literário das relações diplomáticas do Egito da história.

\section{As cartas}

Conforme as cartas eram encontradas pelos arqueólogos, a grande maioria foi destinada imediatamente aos museus do Cairo, Europa e EUA. Poucas cartas foram parar nas mãos de colecionadores privados. Isso permitiu que fossem reunidas e publicadas com bastante rapidez (MYNAROVÁ, 2015, p. 40-41). ${ }^{32}$ Evidentemente que a novidade da descoberta, sua importância para a história e a relação com as terras do mundo da Bíblia contribuíram para que assim fosse. O que não quer dizer que o processo da tradução tenha sido simples. Pelo grande número de cartas, a participação de várias pessoas em diferentes estágios, a história da tradução das cartas é bem complexa (RAINEY, 2015, p. 6-7). Há cartas que têm história própria, como a EA 265, da qual foi publicada somente a transcrição. O paradeiro do texto cuneiforme não se sabe, bem como, do tablete. Ou de outras, como a EA 7, cujo original foi publicado, mas o tablete foi destruído no bombardeio de Berlim em 1945, ou ainda a EA 135, que ficou deteriorada por um vazamento de água no museu de Ashmolean, em Oxford, com alguns tabletes de exercícios dos escribas (RAINEY, 2015, p. 6-10).

\footnotetext{
31 Também foram achados fragmentos de exercícios de escribas, prova de que em Amarna tinha uma escola ou escolas de escribas de cuneiforme (IZRE’EL, 1997, p. 12). Também há cartas do período de Amarna que foram encontradas fora da cidade de Amarna, como as descobertas nos sítios de Taanac, Siquém e Hazor.

32 Diferente, por exemplo, do que sucedeu com os pergaminhos de Qumrã.
} 


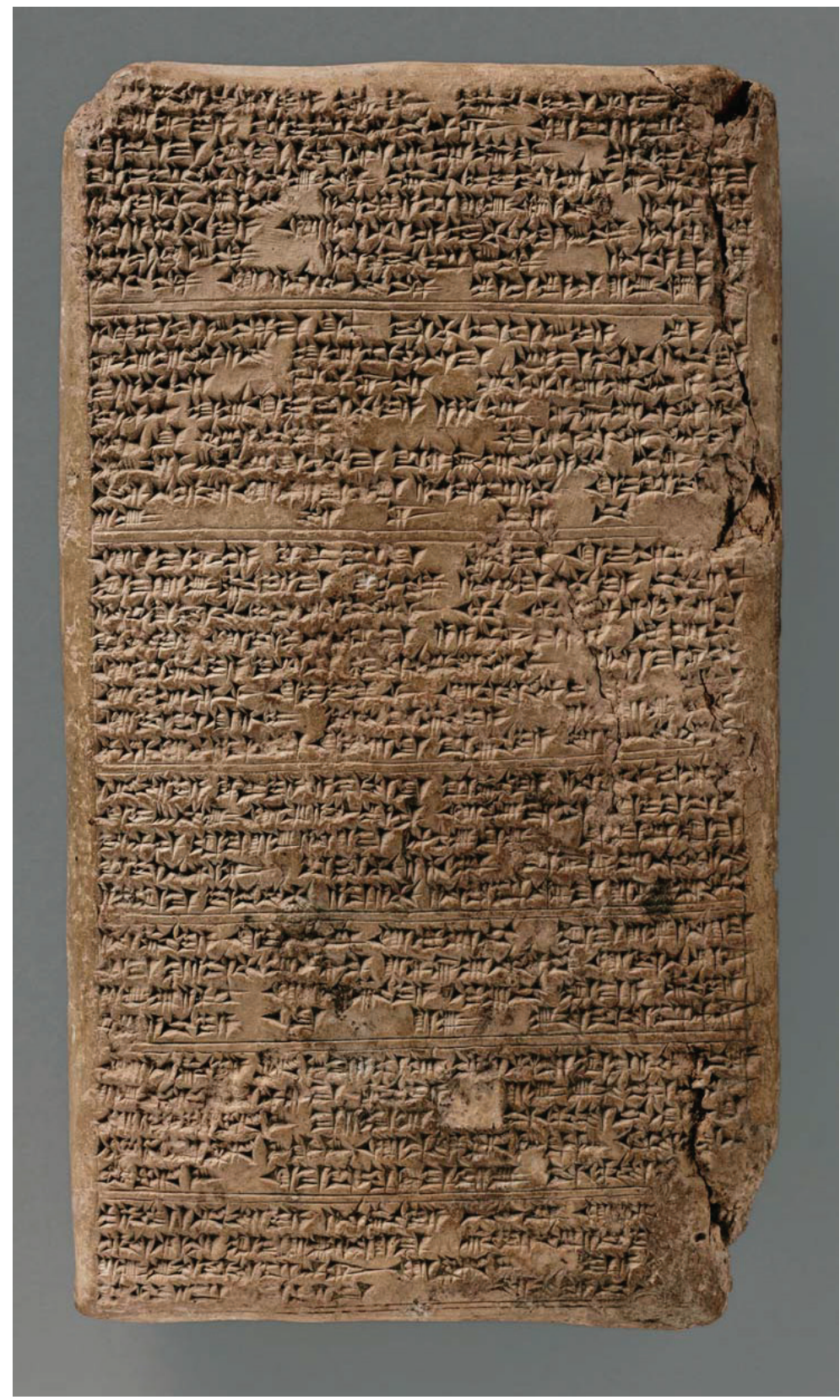

Frente da carta EA 19 escrita por Tusarata de Mitani ao faraó Amenhotep III. Também o verso é todo escrito (gentileza do museu britânico). 
Uma das maiores referências, quando se trata da tradução das cartas de El-Amarna, é a publicação de Jorgen Alexander Knudtson, em $1915 .{ }^{33}$ Ele reuniu e editou as primeiras 358 cartas. Foi também ele quem viu todas as cartas pela última vez e que estabeleceu a ordem numérica $\mathrm{EA}$, considerando a cronologia, a geografia e a função (RAINEY, 2015, p. 8). Essa ordem, porém, que prevalece até hoje, não é muito segura, assim como o local exato da origem de muitas cartas. Os tabletes encontrados após o trabalho de Knudtson tiveram a participação de vários linguistas, em diferentes etapas, com destaque para os trabalhos de C. H. Gordon, em 1947, de A. F. Rainey, em 1970, 1978 e 2015, e de W. L. Moran, em 1987, entre outros.

\subsection{A escrita cuneiforme do Médio Babilônico}

O impressionante do achado das cartas de El-Amarna foi o de revelar a existência de uma sofisticada rede de relações diplomáticas entre o Egito e praticamente o restante do mundo conhecido. O conjunto das cartas encontradas de El-Amarna contém correspondências vindas da longínqua Anatólia (Hati), de Mitani, Ugarit, Amurru, Damasco, Assíria, Babilônia, Arzawa, Alashia, Biblos etc., e de quase todos os reinos de Canaã, sem contar os lugares, cuja localização não tem sido possível identificar até agora. Como era possível se comunicar com todos esses reinos? Pelas cartas de El-Amarna, descobriuse que o Egito adotou uma língua comum, curiosamente não egípcia, mas cuneiforme, acádica. Com exceção de algumas cartas, como a EA 24, escrita em hurrita, e as EA 31 e 32, escritas em hitita, as demais são todas escritas tendo como base o acádico babilônico médio (MORAN, 1992, p. 28; RAINEY, 2015, p. 10-11). Ou seja, as relações diplomáticas do Egito não aconteciam via linguagem egípcia. Os egípcios fizeram uso de uma linguagem que já no final do terceiro milênio e início do segundo estava espalhada pelos grandes centros comerciais da Mesopotâmia como via oficial das transações internacionais. Evidentemente que com variações de região para região, resultado da influência dos dialetos locais, como o hurro-acádico do norte da Assíria (MORAN, 1992, p. 28-31).

Como os escribas egípcios dominavam todos esses dialetos, é uma incógnita. É possível que em El-Amarna houvesse um especialista de cada região que auxiliava na leitura das cartas. Da mesma forma, não era fácil que

33 Linguista e assiriólogo norueguês (1854-1917), professor da Universidade de Oslo. Sua obra de referência: Die El-Amarna-Tafeln. Mit Einleitung und Erläuterungen, publicada em dois volumes em 1915 e reeditado em 1964. 
cada reino tivesse um escriba que dominasse a língua acádica. Por isso, muitas cartas têm como remetente um vassalo de determinado lugar, enquanto a matéria-prima, a argila, provém de outra região (GOREN; FINKELSTEIN; NA'AMAN, 2004). Ou seja, não tendo um escriba competente, o rei local era obrigado a se dirigir à outra cidade-Estado para mandar escrever a carta.

O curioso é que as correspondências de Canaã têm uma vertente própria. Além de terem como base o acádico babilônico antigo, portanto, não o corrente babilônico médio, elas contêm também um coloquialismo local. Ou seja, a raiz/tronco é o acádico babilônico antigo, mas a flexão verbal é cananita (MORAN, p. 12). Portanto, uma linguagem híbrida própria, que os autores denominaram de "cananita". Isso indica que a escrita em Canaã já vinha se desenvolvendo desde o fim do Bronze Médio, por volta de 1500 a.C., quando o acádico babilônico antigo estava em uso na região. E que, como mostram as cartas de El-Amarna, no século XIV a.C., havia em Canaã uma escrita cuneiforme híbrida própria bem desenvolvida a partir do acádico babilônico, com um corpo de escribas nos principais centros, como Gaza, Gezer, Siquém, Hazor, Gat, e Jerusalém. Mais tarde, no final Bronze Tardio, por volta de 1200 a.C., o sistema das cidades-Estado de Canaã entra em colapso, assim como sua escrita. A causa ainda é uma incógnita, mas ultimamente vem tomando fôlego a teoria de que o agente tenha sido uma seca prolongada que afetou todo o Levante no final do Bronze Tardio (LANGGUT; FINKELSTEIN; LITT, 2013, p. 149-174). O fato é que a escrita em Canaã declina até desaparecer por completo por cerca de três séculos. Ela só ressurgirá timidamente entre os séculos X ou IX a.C., nos reinados da dinastia omrida ou de Jeroboão II, agora como paleo-hebraico. Contudo, foi tempo suficiente para que a escrita "cananita" nos deixasse uma série de informações acerca do contexto político, social e econômico da região que, mais tarde, será o palco da formação dos povos da Bíblia, comumente chamados de Israel.

\section{Considerações finais}

A riqueza construída pelo Egito, com seus monumentos milenares, expressa a imponência e o poderio do que representou esse império e o impacto que causava sobre, principalmente, os pequenos reinos cananeus, que sobreviviam sob seu constante domínio. A XVIII dinastia, após a expulsão dos hicsos, atingiu o auge desse desenvolvimento econômico e expansivo. Fator esse que permitiu aos reinados de Amenhotep III e Amenhotep IV, período correspondente às cartas de El-Amarna, uma estabilidade político-econômica 
invejável. A tal ponto que esses dois reis pudessem se ocupar essencialmente com questões internas de seu país. O primeiro investiu sobremaneira na arte e em construções e monumentos que guardassem seu nome para a História. O segundo foi mais além, interveio na religião, tirou o poder da classe sacerdotal, destituiu o Deus Amon-Rá do panteão egípcio e elevou como deus único a Aton, o disco solar. Para ter êxito em sua empreitada, Amenhotep IV mudou seu nome para Akenaton, construiu uma nova cidade, Aketaton (El-Amarna), ao seu deus e transferiu para lá a capital. A nova religião introduziu uma nova teologia, centrada na família real, muito menos guerreira e mais afável. Houve uma passagem do rei-deus para o deus-rei, pois Aton está presente no mundo na pessoa do rei e de sua família. Os novos templos, sem teto, para que os raios solares de Aton penetrassem em todos os rincões, expressam tal realidade.

A ênfase no culto a Aton fez Akenaton deixar de lado a política externa, a ponto de, em poucos anos, o Egito estar mergulhado em um grande caos político. Assim, quando Akenaton morre, morre também sua revolução. Seu sucessor, Tutankaton, muda de nome para Tutankamon, reintroduz o culto a Amon-Ra e abandona a cidade de Aketaton (El-Amarna), retornando a capital para Tebas. Ao abandonar Aketaton, Tutankamon deixa também ali as correspondências internacionais, tanto as de Akenaton, quanto as de Amenhotep III, trazidas até ali pelos ministros do rei. E ali permaneceram até serem encontradas pelos arqueólogos nos séculos XIX e XX d.C., na agora chamada Tell El-Amarna.

\section{Referências}

BEN-TOR, Daphna (org.). Pharaoh in Canaan -The Untold Story. Jerusalém: The Israel Museum, 2016.

CHALABY, Abbas. All of Egypt - From Cairo to Abu Simbel and Sinai. Florença: Bonechi, 2001.

DAVIS, W. THOMAS. Shifting Sands: The Rise and Fall of Biblical Archaeology. New York: Oxford University Press, 2004.

GOREN, Y.; FINKELSTEIN, I.; NA'AMAN, N. Inscribed in Clay: Provenance Study of the Amarna Letters and other Ancient Near Eastern Texts. Tel Aviv: Tel Aviv University, 2004.

IZRE'EL, Schlomo. The E-Amarna Letters from Canaan. Disponível em: https://www. academia.edu/371049/The_El-Amarna_Letters_from_Canaan.

KEMP, Barry. The City of Akhenaten and Nefertiti - Amarna and its people. London: Thames\&Hudson Ltd, 2012. 
KNUDTSON, J. A. Die El-Amarna-Tafeln. Mit Einleitung und Erläuterungen. Erster Teil Die Texte. Zweiter Teil Anmerkungen und Register bearbeitet von Otto Weber und Erich Ebeling. Leipzig (1915), Aalen: Neudruck, 1964.

LANGGUT, Dafna; FINKELSTEIN, Israel; LITT, Thomas. Climate and the Late Bronze Collapse: New Evidence from the Southern Levant. Tel Aviv, v. 40. Tel Aviv: University Press, 2013, p. $149-174$.

MYNAROVÁ, Jana. Amarna Palaeography Project. The current State of Research. Jana Mynarová, Pavel Onderka e Peter Pavúk (Orgs.). There and Back Again - The Crossroads II. Praga: Charles University in Prague, Faculty of Arts, 2015b, p. 409-422.

MYNAROVÁ, Jana. Discovery, research and excavation of the Amarna Tablets - The formative stage. RAINEY, Anson F. The El-Amarna Correspondence - "A new Edition of the Cuneiform Letters from de Site of El-Amarna based on Collations of all Extant Tablets". Leiden-Boston: Brill, 2015, p. 37-46.

MORAN, William L. The Amarna letters. Baltimore/London: The Johns Hopkins University Press, 1987.

MURnANE, William J. Texts from the Amarna Period in Egypt (Writings from the Ancient World - Society of Biblical Literature). Atlanta: Scholar Press, 1995.

RAINEY, Anson F. The El-Amarna Correspondence - A new Edition of the Cuneiform Letters from de Site of El-Amarna based on Collations of all Extant Tablets. Leiden-Boston: Brill, 2015.

SHAW, Ian; NICHOLSON, Paul. The British Museum Dictionary of Ancient Egypt. Cairo: The American University in Cairo Press, 2002.

TRIGGER, B. G.; KEMP, B. J.; O’CONNOR, D.; LLOYD, A. B. Ancient Egypt - A Social History. Cambridge: Cambridge University Press, 1999.

http://antigoegito.org/cronologia-dinastias/ (acessado em 24/06/2017).

http://www.nationalgeographic.com/magazine/2017/05/akhenaten-revolutionary-egypt-kingart-architecture/ (acessado em 26/06/2017).

Submetido em: 4-9-2017

Aceito em: 23-4-2018 